\title{
A quasi chemistry-transport model mode for EMAC
}

\author{
R. Deckert ${ }^{1}$, P. Jöckel ${ }^{1}$, V. Grewe ${ }^{1}$, K.-D. Gottschaldt ${ }^{1}$, and P. Hoor ${ }^{2}$ \\ ${ }^{1}$ Deutsches Zentrum für Luft- und Raumfahrt, Institut für Physik der Atmosphäre, Oberpfaffenhofen, Germany \\ ${ }^{2}$ Johannes Gutenberg-Universität Mainz, Institut für Physik der Atmosphäre, Germany
}

Received: 21 October 2010 - Published in Geosci. Model Dev. Discuss.: 19 November 2010

Revised: 23 February 2011 - Accepted: 7 March 2011 - Published: 16 March 2011

\begin{abstract}
A quasi chemistry-transport model mode (QCTM) is presented for the numerical chemistry-climate simulation system ECHAM/MESSy Atmospheric Chemistry (EMAC). It allows for a quantification of chemical signals through suppression of any feedback between chemistry and dynamics. Noise would otherwise interfere too strongly. The signal is calculated from the difference of two QCTM simulations, a reference simulation and a sensitivity simulation. In order to avoid the feedbacks, the simulations adopt the following offline chemical fields: (a) offline mixing ratios of radiatively active substances enter the radiation scheme, (b) offline mixing ratios of nitric acid enter the scheme for re-partitioning and sedimentation from polar stratospheric clouds, (c) and offline methane oxidation is the exclusive source of chemical water-vapor tendencies. Any set of offline fields suffices to suppress the feedbacks, though may be inconsistent with the simulation setup. An adequate set of offline climatologies can be produced from a non-QCTM simulation using the setup of the reference simulation. Test simulations reveal the particular importance of adequate offline fields associated with (a). Inconsistencies from (b) are negligible when using adequate fields of nitric acid. Acceptably small inconsistencies come from (c), but should vanish for an adequate prescription of chemical water vapor tendencies. Toggling between QCTM and non-QCTM is done via namelist switches and does not require a source code re-compilation.
\end{abstract}

\section{Introduction}

The recognition of feedback processes in the Earth system is essential to the understanding of past and future changes in the atmospheric chemical composition and climate. Global chemistry-climate models (CCMs) are well suited to inves-

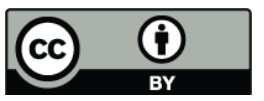

Correspondence to: R. Deckert (rudolf.deckert@dlr.de) tigate such feedbacks, since these models account for the non-linear coupling between atmospheric dynamics, chemistry, radiation, and other processes. However, the presence of feedbacks can hamper the identification of climate effects from, for instance, altered emissions of short-lived anthropogenic substances. This is the case if natural variability, here referred to as noise, disguises the expected signal.

For example, the objective of quantifying the expected impact from changes in nitrogen oxides $\left(\mathrm{NO}_{\mathrm{x}}=\mathrm{NO}+\mathrm{NO}_{2}\right)$ emissions requires a comparison of at least two model simulations: a reference simulation with reference sources of $\mathrm{NO}_{\mathrm{x}}$ and a sensitivity simulation with sources that differ from the reference setup slightly. If the simulations include any feedback between dynamics and chemistry, then the meteorology of the two simulations will diverge despite binary identical initialization due to the inherent chaos in the system, a property commonly referred to as butterfly effect. Such behavior is inevitable, even for the smallest chemically triggered perturbation of the meteorological state. After a small number of time steps with perturbed conditions, the two simulations will differ completely in their meteorological patterns, communicating the meteorological variability to mixing ratios of chemical compounds such as $\mathrm{NO}_{\mathrm{x}}$ (e.g. Unger et al., 2008).

Note that time averages of dynamical variables may be hardly affected, but that the sequence of meteorological weather patterns can be completely different among the two simulations. Hence, day-to-day mixing ratio differences in the two simulations will be governed by noise (Fig. 1a), and estimation of statistical expectation of chemical quantities require long and computationally expensive integrations. The problem is particularly strong when focusing on the quantification of effects from small perturbations of multiple emission sources such as road traffic, shipping, and aviation (e.g. Hoor et al., 2009; Unger et al., 2008).

Feedback processes between atmospheric chemistry and dynamics are manifold. Every chemically and radiatively active compound causes such feedback. Typical examples are ozone $\left(\mathrm{O}_{3}\right)$, methane $\left(\mathrm{CH}_{4}\right)$, chlorofluorocarbons ( $\left.\mathrm{CFCs}\right)$,

Published by Copernicus Publications on behalf of the European Geosciences Union. 


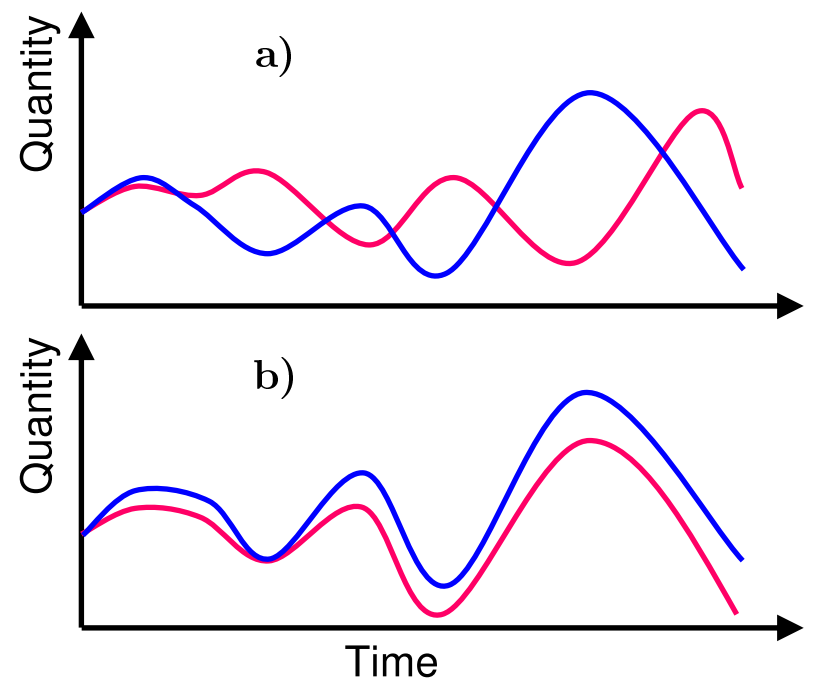

Fig. 1. Mixing ratio $x$ of an arbitrary chemical tracer from two hypothetical simulations. The simulation setups differ only by a small chemical perturbation affecting $x$, and share identical initialization. Note that the simulations have near-identical statistical expectation with respect to dynamical quantities such as divergence and vorticity. However, the feedback between chemistry and dynamics causes a completely different sequence of dynamical patterns and associated tracer transport, and hence a low signal-to-noise ratio for the chemistry-related difference $\Delta x$ among the two simulations (a). Without feedback between chemistry and dynamics, however, $\Delta x$ relates directly to the chemical perturbation, and it displays a high signal-to-noise ratio (b).

and nitrous oxide $\left(\mathrm{N}_{2} \mathrm{O}\right)$. A special species is water vapor $\left(\mathrm{H}_{2} \mathrm{O}\right)$ as it plays an important role not only in the radiation budget, but also in cloud physics and atmospheric chemistry; the latter, for example, as a source of hydroxyl-radical $(\mathrm{OH})$ formation or as a product of stratospheric $\mathrm{CH}_{4}$ degradation.

Also, there are substances which are not radiatively active, but which affect dynamical processes such as properties of clouds. The formation of polar stratospheric clouds (PSCs), for example, depends on species such as $\mathrm{H}_{2} \mathrm{O}$ and nitric acid $\left(\mathrm{HNO}_{3}\right)$. Any minor change in $\mathrm{HNO}_{3}$ mixing ratios will alter PSC formation, and, through the associated $\mathrm{H}_{2} \mathrm{O}$ changes, causes a feedback between chemistry and dynamics.

Yet, chemically triggered changes to the feedback processes themselves are often small enough to be neglected. It is hence feasible to account for the feedbacks between chemistry and dynamics with prescribed climatologies. With this restriction, chemical perturbations will not affect the meteorological patterns, turning chemistry-dynamics feedbacks off. In either of the two example simulations mentioned above, the patterns of atmospheric dynamics are then binary identical and any difference in chemical mixing ratios is directly attributable to the difference in $\mathrm{NO}_{\mathrm{x}}$ emission rates among the two (Fig. 1b). As a result, the differences in chemical mixing ratios have a much higher signal-to-noise ratio.

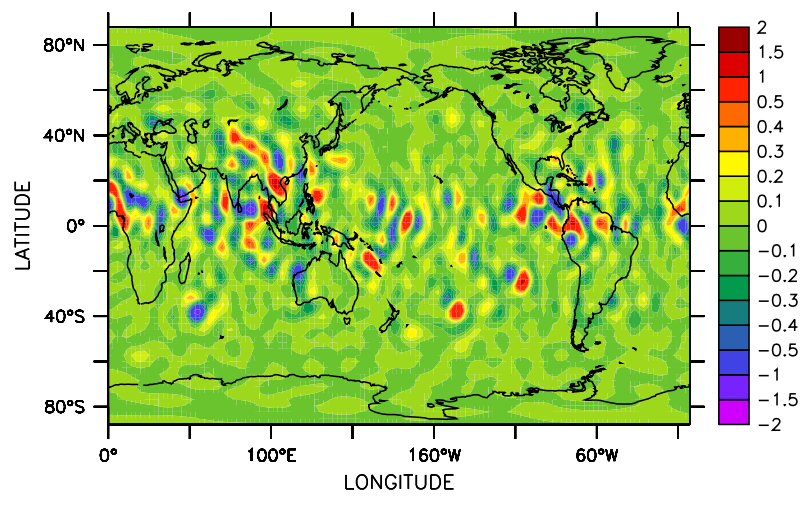

Fig. 2. Snapshot of the difference (in $\mathrm{m} \mathrm{s}^{-1}$ ) in zonal-wind velocity, about $4000 \mathrm{~m}$ above ground, between two nudged simulations in coupled mode with the CCM EMAC. Output time: 4 June at seven p.m., $19 \mathrm{~h}$ after initialization. The simulations share identical setup, initialization, executable, and nudging. The only difference is a $5 \%$ anomaly in $\mathrm{NO}$ emissions from road traffic.

We say a CCM is run in quasi chemistry-transport model mode (QCTM) when any impact from the model chemistry on the dynamics is switched off. The opposite case with active feedbacks between chemistry and dynamics is referred to as coupled mode, or coupled simulation. The term "quasi" serves to distinguish from pure chemistry-transport models which do not integrate the prognostic dynamical equations. The model setup determines also other model characteristics such as resolution, boundary conditions, and the selection of active submodels. Offline chemical characteristics are imposed on a simulation from outside, whereas online chemical characteristics are part of the simulation's chemistry integration.

The nudging method (e.g. Jöckel et al., 2006) does not represent an appropriate alternative to the QCTM. As the term implies, nudging is a weak Newtonian relaxation of the internally calculated dynamical tendencies towards a prescribed meteorological state. At the same time, parameterizations and small-scale dynamical processes are not subject to any direct nudging. Hence, the butterfly effect is still present and binary identity, as defined above, not given. Figure 2 exemplifies the issue. It shows the difference in zonal-wind velocity between two nudged simulations with the CCM EMAC (see Sect. 2). The simulations obey the scenarios BASE and ROAD in Hoor et al. (2009), thus differ in a 5\% disparity of NO emission from road traffic, but otherwise share identical setup, initialization, executable, and nudging of dynamical tendencies. A few hours after initialization, the smallscale dynamical features have diverged due to the feedback between dynamics and chemistry, generating a low signalto-noise ratio for the difference in mixing ratios of chemical substances such as $\mathrm{CO}$ or $\mathrm{O}_{3}$ (not shown). Yet, the nudging will prevent the model dynamics from complete divergence. 
This documentation presents a QCTM implemented into the CCM ECHAM/MESSy Atmospheric Chemistry (EMAC), version 1.10. It is going to be released in version 1.11. Section 2 introduces the model system EMAC, and Sect. 3 gives specific information on those submodels of EMAC which are important to the QCTM. Section 4 evaluates the QCTM. Following the conclusions of Sect. 5, the Appendix informs on how to use the QCTM.

\section{Model system EMAC}

EMAC is a numerical chemistry and climate simulation system that includes submodels describing tropospheric and middle atmosphere processes and their interaction with oceans, land, and human influences (Jöckel et al., 2006). It uses the first version of the Modular Earth submodel System (MESSy1) to link multi-institutional computer codes. The core atmospheric model is the 5th generation European Centre Hamburg general circulation model ECHAM5 (Roeckner et al., 2006). More detailed information, including references, about the model system is available from http://www.messy-interface.org.

The core model of EMAC, ECHAM5, solves the atmospheric primitive equations horizontally via a spectral transform technique. In the vertical it uses the method of finite differences and for time integration a semi-implicit leap-frog scheme with time filter.

Most of the EMAC submodels act on a Gaussian transform grid and, e.g., handle parameterized physics, transport of atmospheric constituents, and atmospheric chemistry. Depending on the complexity of the chemistry setup, the chemical calculations usually consume a large portion of the total central-processing-unit time. Chemistry is dealt with by the submodel MECCA1 (Sander et al., 2005), which is based on the kinetic pre-processor (KPP) software (Damian et al., 2002) and considers the combined chemical reactions as a stiff system of ordinary differential equations. The system is solved via a Rosenbrock sparse-matrix technique with adaptive time step.

The parallelization is implemented based on the distributed memory concept with different approaches for the spectral and the grid-point representation, and a specific representation for the tracer advection algorithm, respectively. In spectral representation, variables are decomposed into their spherical harmonics, and in Gaussian representation the global domain is decomposed into blocks in latitudinal and longitudinal direction. For the advection an additional vertical decomposition is applied. For each variable in Gaussian representation two blocks at the same longitude and the same latitude are combined, with one block being in the Northern and one block in the Southern Hemisphere. This improves the load balancing with respect to the distribution of day and night grid boxes. The combined blocks are further re-arranged into vectors of selectable length to optimally ex- ploit vector registers on vector architectures and cache sizes on scalar architectures.

\section{Specific submodels and QCTM implementation}

The implementation of the QCTM involves the EMAC submodels RAD4ALL, H2O, HETCHEM, and PSC, which are commented on here. Switching between QCTM and coupled mode does not require a re-compilation of the EMAC source code, so that the same executable can be used for both modes. Instead, it requires the modification of certain switches and adjustments in the respective namelists (see Table A1).

\subsection{Submodel RAD4ALL}

The submodel RAD4ALL (see Jöckel et al., 2006) is a reimplementation into the MESSY standard of the ECHAM5 radiation code (Roeckner et al., 2006). In coupled mode, RAD4ALL relies on online fields for the calculation of radiative transfer. These are with regard to the hydrological cycle: cloud cover, cloud water, cloud ice, prognostic specific humidity; and with regard to the radiatively active chemical species: $\mathrm{CO}_{2}, \mathrm{CH}_{4}, \mathrm{O}_{3}, \mathrm{~N}_{2} \mathrm{O}, \mathrm{CFC}-11$, $\mathrm{CFC}-12$, depending on the chemical setup.

For the QCTM, the mixing ratios of all radiatively active chemical species, except for the $\mathrm{H}_{2} \mathrm{O}$ tracer, must be provided from offline climatologies. The relevant switches are located in the coupling namelist (CPL) of the RAD4ALL submodel, and the respective offline fields are defined via the REGRID and RGTEVENTS namelists of RAD4ALL (see Table A1). Note the model chemistry still provides online mixing ratios of the radiatively active species, but these are not used by the RAD4ALL submodel in case the QCTM is active.

\subsection{Submodel H2O}

The submodel $\mathrm{H} 2 \mathrm{O}$ serves several purposes. It creates and initializes the gas-phase tracer $\mathrm{H}_{2} \mathrm{O}$ as part of the model chemistry, in contrast to the specific humidity being inherent to the ECHAM5 core model. To clearly separate these two aspects, we will refer to the water vapor fields from the $\mathrm{H} 2 \mathrm{O}$ submodel as $\mathrm{H}_{2} \mathrm{O}$ tracer, and to the water vapor field from ECHAM5 as specific humidity. Additionally, it provides an option to use for the $\mathrm{H}_{2} \mathrm{O}$-tracer tendency a climatology associated with $\mathrm{CH}_{4}$ oxidation. Finally, it controls the feedback between the $\mathrm{H}_{2} \mathrm{O}$ tracer and the specific humidity via synchronization. For any model time step after initialization, the synchronization first replaces value and tendency of the $\mathrm{H}_{2} \mathrm{O}$ tracer by those of the specific humidity. Then, chemical processes bring about a new tendency of the $\mathrm{H}_{2} \mathrm{O}$ tracer, either as online field from a chemistry submodel, or as climatology from the $\mathrm{H} 2 \mathrm{O}$ submodel itself, or as a sum of the two. Last, the new tendency replaces that of the specific humidity. Any 
replacement in either direction takes into account the different units of measurement.

The details of the last replacement depend on the I_H2O_TENDENCY switch in the CPL namelist of the $\mathrm{H} 2 \mathrm{O}$ submodel (see Appendix B). The preferred setting for the QCTM is I_H2O_TENDENCY $=2$, implying an exclusive usage of offline water vapor tendencies. These offline fields are calculated based on a satellite climatology of $\mathrm{CH}_{4}$ mixing ratios and pre-calculated climatological conversion rates from a coupled simulation. The default involves monthly average conversion rates from a MAECHAM4/CHEM simulation (Steil et al., 2003) which correspond to photolysis and oxidation of $\mathrm{CH}_{4}$ by $\mathrm{OH}, \mathrm{O} 1 \mathrm{D}$, and $\mathrm{Cl}$. Alternative input data may be selected through the submodel namelists.

\subsection{Submodel HETCHEM}

The submodel HETCHEM computes heterogeneous reaction rates for surfaces associated with solid nitric acid trihydrate (NAT), ice, super-cooled ternary solutions, and aerosols. As to the present study, a climatology of sulfuric-acid mixing ratios as used by Jöckel et al. (2006) serves as the basis for heterogeneous reactions on sulfate aerosol such as $\mathrm{N}_{2} \mathrm{O}_{5}+\mathrm{H}_{2} \mathrm{O} \rightarrow 2 \mathrm{HNO}_{3}$.

Tendencies of the water cycle associated with the repartitioning of the three phases are neglected in case L_COUPLE_H2O $=\mathrm{F}$ in the HETCHEM-namelist CPL (see also Table A1). This setting prevents water-mediated impact of heterogeneous chemistry on the dynamics.

\subsection{Submodel PSC}

PSCs affect the stratospheric chemistry and chemical composition by heterogeneous reactions occurring on both liquid and solid cloud particles, and by sedimentation of the solid cloud particles. The submodel PSC takes these effects into account and it further determines heterogeneous reaction rates. Also, it establishes the vertical redistribution of $\mathrm{H}_{2} \mathrm{O}$ and $\mathrm{HNO}_{3}$ due to sedimentation of ice particles, referred to as dehydration, and due to sedimentation of NAT particles, referred to as denitrification.

First, the thermodynamic partitioning of $\mathrm{H}_{2} \mathrm{O}$ and $\mathrm{HNO}_{3}$ is accomplished. For the determination of particle size there are two different schemes. The one assumes that the particles have all the same size (Buchholz, 2005). The other one considers a discrete size distribution (Kirner et al., 2011) and has not yet been tested in QCTM. Thereafter, the PSC submodel determines the vertical re-distribution of $\mathrm{H}_{2} \mathrm{O}$ and $\mathrm{HNO}_{3}$ through particle sedimentation.

The numerical scheme is restricted to those atmospheric regions where PSCs are allowed to exist. The user prescribes an equatorward latitude limit as well as upper and lower pressure bounds to avoid PSCs where observations do not support their existence. Inside these pre-defined regions, the PSC submodel performs any PSC-related calculation only where the current local equilibrium temperature of ice is smaller than that of NAT.

The PSC submodel causes feedback between dynamics and chemistry through the following processes:

1. It defines heterogeneous chemical reactions via the HETCHEM submodel. These, in turn, alter the distribution of radiatively active substances through the chemistry submodel MECCA1. The RAD4ALL radiation submodel then communicates the chemical perturbation to the dynamics. In case of water vapor, the hydrological cycle represents an additional communication path.

2. Sedimentation-caused mixing ratio changes of $\mathrm{H}_{2} \mathrm{O}$ depend on $\mathrm{HNO}_{3}$ through ice particle size and partitioning. Again, hydrological cycle and radiation close the feedback towards the model dynamics.

3. The amount of $\mathrm{HNO}_{3}$ determines which thermodynamic phases are stable and thus impacts on the PSCrelevant regions (see above). For these regions, the CLOUD submodel suppresses the occurrence of any cirrus clouds, hence generating feedback. Additionally, the PSC-relevant regions re-enter the PSC submodel in the next time-step.

A removal of the PSC-related feedbacks by avoiding PSCs at all would be trivial to do. However, PSCs are important to the Earth system, e.g. through their impact on stratospheric ozone mixing ratios and dynamics, and should be accounted for. Rather than having no PSCs at all, it is hence better to remove only the PSC-related feedbacks.

The QCTM settings in the submodels HETCHEM and $\mathrm{H} 2 \mathrm{O}$ (see Sects. 3.2, 3.3 and Table A1) remove any feedback associated with item 1 in the above list. Items 2 and 3 represent feedback through non-chemical mechanisms which involve $\mathrm{HNO}_{3}$. Figure 3 illustrates how the feedback removal is implemented in this case. The main idea is to replace online total- $\mathrm{HNO}_{3}$ mixing ratios by an offline climatology where necessary in the code, while affecting PSC-related effects such as sedimentation as little as possible.

Partitioning within PSCs is therefore evaluated twice:

1. using an offline total- $\mathrm{HNO}_{3}$ climatology in order to make the following quantities and characteristics independent of the KPP-solved chemistry: water vapor tendencies, particle radii, and thermodynamic phase. The water vapor tendencies and particle radii go into the sedimentation scheme. In a similar way, the thermodynamic phase goes into the cirrus-related computations by the CLOUD submodel.

2. using online total- $\mathrm{HNO}_{3}$ fields from the KPP chemistry solver. As an important consequence of the double calculation, PSC-related partitioning/sedimentation induces KPP-dependent $\mathrm{HNO}_{3}$ tendencies which remain in the chemistry domain and do not affect the dynamics. 


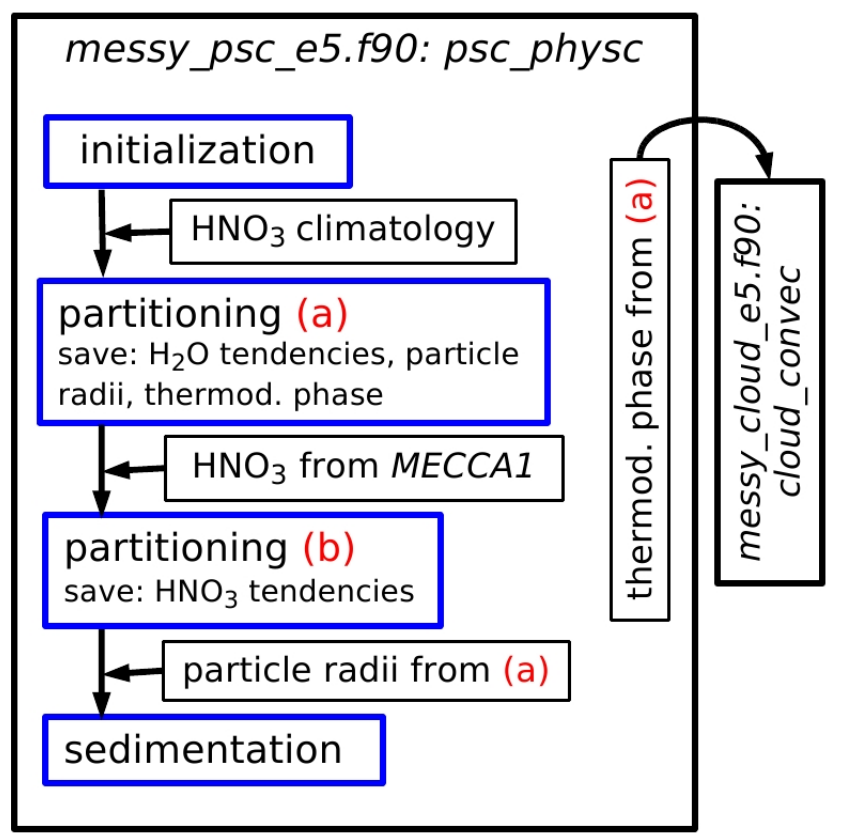

Fig. 3. Flowchart of how the QCTM is implemented into the EMAC submodel PSC. The partitioning is calculated twice using (a) offline, and (b) online mixing ratios of $\mathrm{HNO}_{3}$ (see text for more detailed explanations).

Yet, the specific humidity tendencies remain unaffected by KPP as these would otherwise establish a feedback between dynamics and chemistry.

Table A1 informs about the namelist settings which make the partitioning QCTM conform.

\section{Evaluation of EMAC in QCTM}

This section presents and discusses EMAC simulations in QCTM and coupled mode. Section 4.1 demonstrates that the QCTM has been successfully implemented into EMAC. It gives an example where sensitivity simulations and reference simulations in coupled mode fail to provide meaningful results due to a low signal-to-noise ratio. Based on this exemplary situation, the QCTM is shown to perform and to tackle the underlying scientific problem.

Section 4.2 evaluates the QCTM-related effects on dynamical and chemical characteristics of the atmosphere. This is accomplished through a comparison of simulation pairs that differ only by the settings required to switch between QCTM and coupled mode.

\subsection{Demonstration of performance}

Figure 4 shows the relative difference in $\mathrm{O}_{3}$ mixing ratios between a sensitivity simulation and its reference simulation in QCTM (a and c) and fully coupled mode (b and d).
The sensitivity simulation differs from the reference simulation by $5 \%$ stronger emissions from biomass burning of $\mathrm{CO}$, non- $\mathrm{CH}_{4}$ volatile organic compounds (NMVOCs), and $\mathrm{NO}_{\mathrm{x}}$. The setup for the simulations is T42L90MA with EVAL chemistry (Jöckel et al., 2006), and includes the submodels CLOUD, CONVECT, CVTRANS, DRYDEP, H2O, HETCHEM, JVAL, LNOX, MECCA1, OFFLEM, ONLEM, PSC, QBO, RAD4ALL, SCAV, TNUDGE, and TROPOP. There is no nudging of the dynamical variables. The model setup is for conditions of the year 2000 and we analyze the seventh month, July, after initialization. This implies nonequilibrium conditions, but is sufficient for demonstration purposes.

In the presence of $\mathrm{NO}_{\mathrm{x}}$ and sunlight, oxidation of $\mathrm{CO}$ and NMVOCs produces $\mathrm{O}_{3}$ in a complicated nonlinear way (Unger et al., 2008). The chemical scheme which has been evaluated by Jöckel et al. (2006) and which we adopted in our simulations accounts for the nonlinear ozone production. The nonlinearity implies considerable complexity of the impact on tropospheric chemical composition by altered $\mathrm{NO}_{\mathrm{x}}$, $\mathrm{CO}$, and NMVOC emissions; Yet, the perturbation in emissions between sensitivity and reference simulation is small (5\%), and applied to $\mathrm{CO}, \mathrm{NMVOC}$, and $\mathrm{NO}_{\mathrm{x}}$ simultaneously. It is hence reasonable to assume throughout the following discussion that their tropospheric mixing ratios, together with those of $\mathrm{O}_{3}$, should be higher for the sensitivity simulation with its stronger emissions.

In the QCTM simulation, there is a clear positive anomaly in the troposphere of $\mathrm{O}_{3}$ (Fig. 4a and c), $\mathrm{NO}_{\mathrm{x}}$ (Fig. 5), $\mathrm{CO}$, and the NMVOCs (not shown). The anomaly is solely due to the chemistry as the dynamical states of sensitivity and reference simulation are binary identical (not shown). It is emphasized that the amplitude of the mixing ratio anomaly is similar for snapshot (Fig. 4a) and monthly average (Fig. 4c). The reason is that the sensitivity simulation, compared to the reference simulation, has biomass burning emission rates which are enhanced by a constant percentage $(5 \%)$ and which include no day-to-day variability. However, the anomaly pattern is spatially less variable for the monthly mean, due to the smoothing of the day-to-day tracer transport variability. Note in this context that the spatio-temporal transport variability is binary identical for sensitivity and reference simulation in QCTM, in contrast to that in coupled mode. Finally, the $\mathrm{O}_{3}$ response is consistent with the general situation. Enhanced African biomass burning causes higher near-surface mixing ratios of $\mathrm{NO}_{\mathrm{x}}$ (Fig. 5), CO, and NMVOC (not shown) just north of the Equator. The enhanced mixing ratios are transported upwards by convection, and southward by the Hadley circulation, increasing the $\mathrm{O}_{3}$ mixing ratios on their way.

The coupled mode, in contrast, does not give a consistent result (Fig. 4b and d). Instead of a widespread positive pattern, there are noisy patches of both positive and negative anomalies, which also applies to $\mathrm{NO}_{\mathrm{x}}, \mathrm{CO}$, and the NMVOCs (not shown). Such behavior indicates transport-related interference with the chemical signal as the 

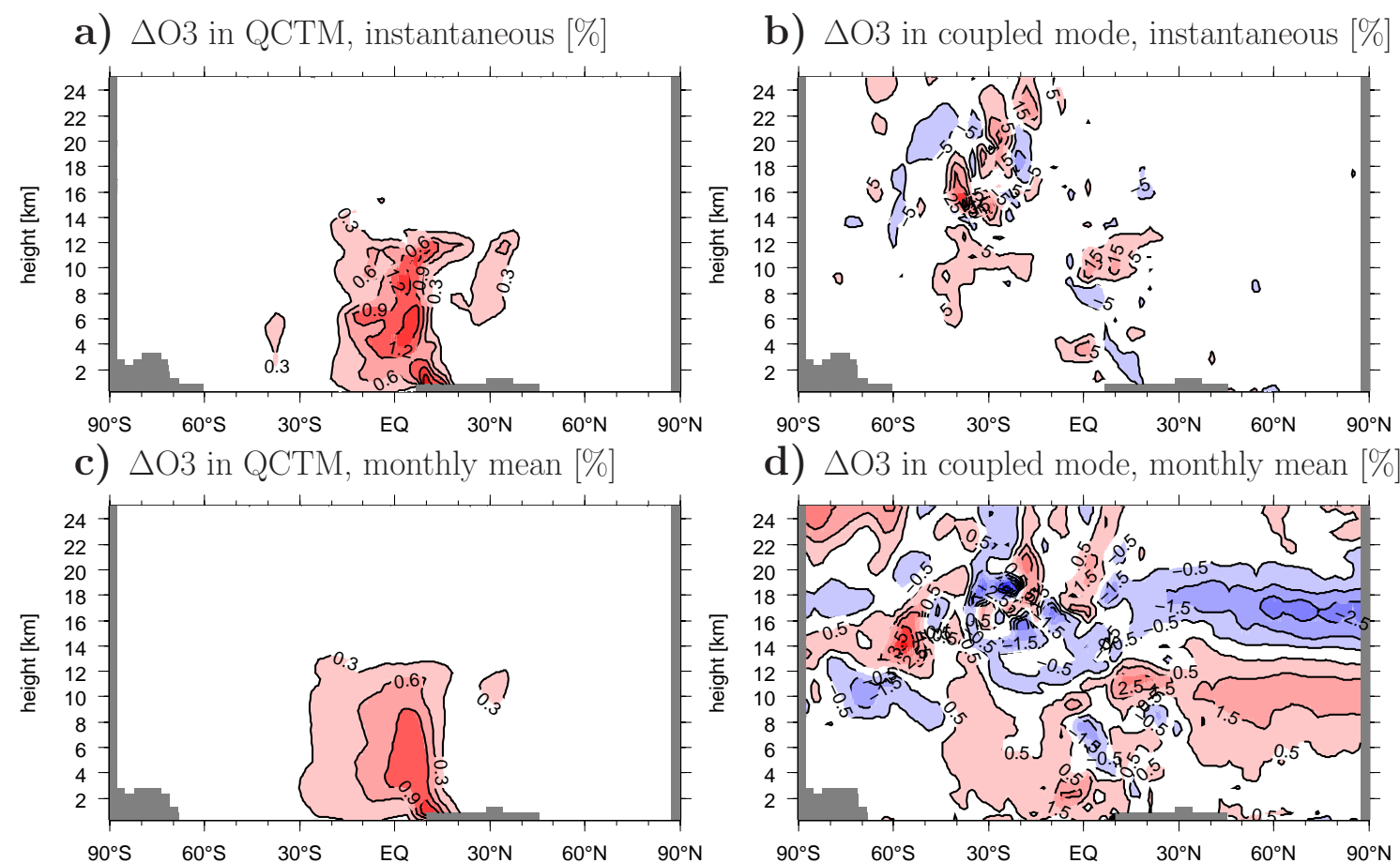

Fig. 4. Latitude-height section of the relative difference in $\mathrm{O}_{3}$ mixing ratios between sensitivity and reference simulation in QCTM (left) and fully coupled mode (right). The sensitivity simulation has $5 \%$ stronger emissions from biomass burning of $\mathrm{NO}_{x}, \mathrm{CO}$, and $\mathrm{NMVOC}$, affecting $\mathrm{O}_{3}$ mixing ratios chemically (see text). Results are shown for the Greenwich Meridian for a single month under July conditions: 00:00 UTC on 1 July (top), monthly mean (bottom). Isoline intervals are $0.3 \%$ in QCTM (left), but $10 \%$ in coupled mode for the instantaneous case (top right), and $1 \%$ for the monthly mean (bottom right). Positive values (red) denote higher $\mathrm{O}_{3}$ mixing ratios for the sensitivity simulation.

$\triangle \mathrm{NOx}$ in QCTM, monthly mean [\%]

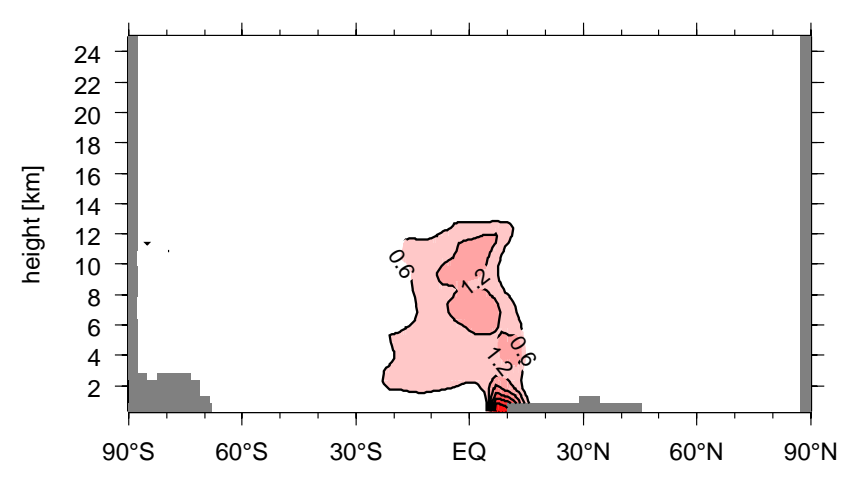

Fig. 5. Same as Fig. 4c, but for $\mathrm{NO}_{\mathrm{x}}$. Isoline intervals are $0.6 \%$.

dynamical states have diverged between the two simulations despite binary identical initialization, as sketched in Fig. 1a. This is due to the feedback between chemistry and dynamics (see Sect. 1). Note that the anomalies are significantly weaker for the monthly averaging (Fig. 4d) than for the instantaneous snapshot (Fig. 4b). Such behavior is likely to result from the averaging which acts as a low-pass filter on the spectrum of atmospheric dynamics, and hence on tracer mixing ratios. Applying statistical analysis to quantify, or even identify, a chemical signal would be a fruitless endeavor due to the overwhelming noise.

\subsection{Impact on simulation climatologies}

The removal of chemistry-climate feedbacks from EMAC represents an interference with the model chemistry and dynamics and it is important to evaluate the associated side effects. In this context, we compare simulations in coupled mode against a simulation in QCTM. We assume that such a comparison also serves to check whether the side effects cause significant inconsistencies for the QCTM simulation itself.

The setup for all simulations is T42L90MA with EVAL chemistry (Jöckel et al., 2006), and includes the submodels CLOUD, CONVECT, CVTRANS, DRYDEP, H2O, HETCHEM, JVAL, LNOX, MECCA1, OFFLEM, ONLEM, PSC, QBO, RAD4ALL, SCAV, TIMEPOS, TNUDGE, and TROPOP. Each experiment covers five years with nudging of tropospheric dynamics towards ECMWF operationalanalysis fields for the period 1999 to 2003.

Figure 6a reveals significant discrepancies in temperature between two simulations, one in fully coupled mode and one in QCTM (see Table 1). The largest discrepancies occur above the $1 \mathrm{hPa}$ level, culminating near the uppermost 

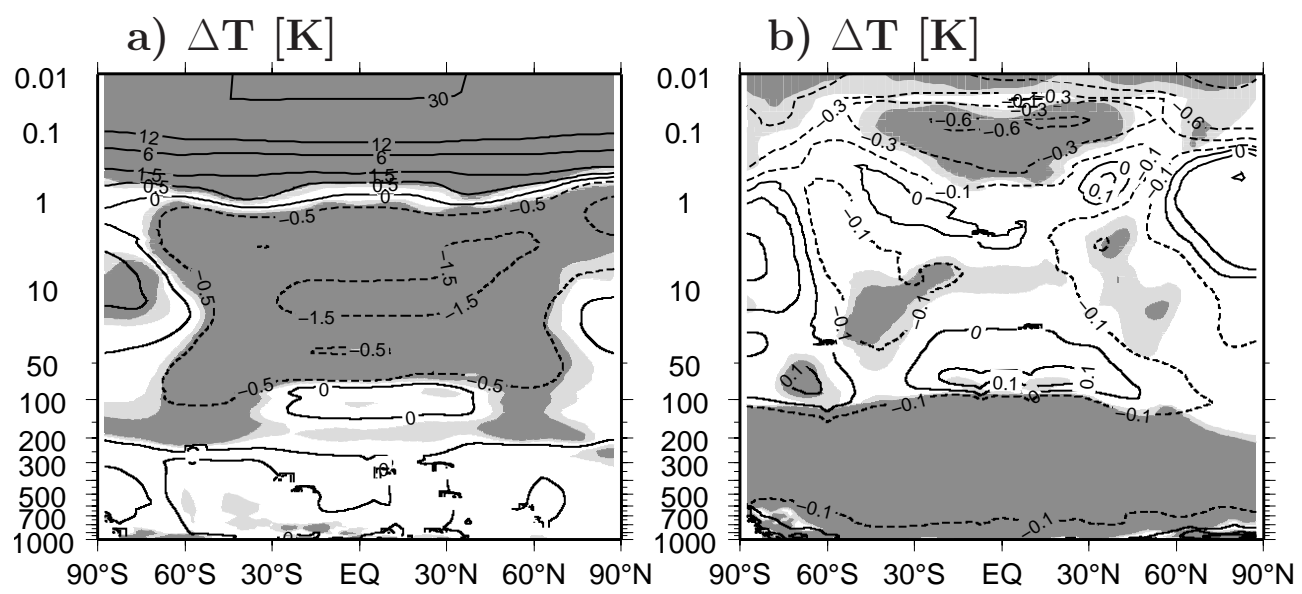

Fig. 6. Zonally averaged annual-mean temperature deviation (isolines in [K]) for the five simulation years 1999-2003. Shading refers to the 99\% (dark-gray) and 95\% (light-gray) significance levels from a paired t-test with four degrees of freedom. (a) simulation decoup_full minus coup_full. (b) coup_rad minus coup_full. Table 1 presents the simulation setups.

model layer in a $+30 \mathrm{~K}$ temperature difference, $\mathrm{a}+50 \%$ difference in relative humidity (Fig. 7c), and a $-60 \%$ difference in ozone mixing ratios (not shown). A further distinct feature is a widespread pattern of opposite sign showing negative temperature differences in the height region between $1 \mathrm{hPa}$ and $100 \mathrm{hPa}$.

Two additional test simulations are performed in order to unravel the mechanisms behind these discrepancies. These simulations are identical to the QCTM simulation mentioned above except that in each case a single coupling pathway remains switched on. One simulation includes the coupling due to radiative effects, the other the coupling associated with PSCs (see Table 1).

Obviously, the removal of radiative-feedback effects explains the lion's share of the temperature discrepancies above the $100 \mathrm{hPa}$ level (see Fig. 6b); for the following reason: in coupled mode, the radiation scheme uses online mixing ratios of the radiatively active species, except for $\mathrm{CO}_{2}$, whereas it relies on offline mixing ratios in the QCTM. Note that the mixing ratios of $\mathrm{CO}_{2}$ are identical for both setups.

For the particular case presented here, the QCTM setup adopts horizontally uniform, height-decreasing, mixing ratios of CFC-11, CFC-12, $\mathrm{N}_{2} \mathrm{O}$, and $\mathrm{CH}_{4}$. The mixing ratios of $\mathrm{CO}_{2}$ are uniform, while those of $\mathrm{O}_{3}$ are taken from Fortuin and Kelder (1998). The $\mathrm{O}_{3}$ climatology by Fortuin and Kelder (1998) extends up to the $0.3 \mathrm{hPa}$ pressure level, well below the highest model layer which is centered at the $0.01 \mathrm{hPa}$ pressure level. For the model layers above the $0.3 \mathrm{hPa}$ pressure level we use height-constant $\mathrm{O}_{3}$ mixing ratios from the uppermost layer of the climatology, about $1.6 \times 10^{-6} \mathrm{~mol} \mathrm{~mol}^{-1}$, the exact value being latitude dependent. The result is significantly lower mesospheric $\mathrm{O}_{3}$ concentrations compared to the online-calculated $\mathrm{O}_{3}$ concentrations (see Fig. 7b), and it must impact on the shortwave radiative heating (e.g. WMO, 2007). Finally, the radiation scheme employs the prognostic specific humidity which, in coupled mode, depends on the KPP chemistry solver via the $\mathrm{H}_{2} \mathrm{O}$ tracer, but not in QCTM (see Sect. 3.2).

The relative differences for $\mathrm{N}_{2} \mathrm{O}, \mathrm{CFC}-11, \mathrm{CFC}-12$, and $\mathrm{CH}_{4}$, offline versus online, share the same basic features in the stratosphere as well as the mesosphere. To give an example, Fig. $7 \mathrm{a}$ depicts the $\mathrm{N}_{2} \mathrm{O}$ difference. The offline case displays positive deviations at all latitudes above the $1-0.1 \mathrm{hPa}$ height region, the exact height being species dependent. The disparity increases strongly towards the uppermost model layer where, at the same time, the mixing ratios are small. The absolute deviations are hence weak, of the order of $10^{-14} \mathrm{~mol} \mathrm{~mol}^{-1}$ for CFC-11 and CFC-12, $10^{-9} \mathrm{~mol} \mathrm{~mol}^{-1}$ for $\mathrm{N}_{2} \mathrm{O}$, and $10^{-7} \mathrm{~mol} \mathrm{~mol}^{-1}$ for $\mathrm{CH}_{4}$. Below the $1-0.1 \mathrm{hPa}$ height region, there are positive deviations poleward of the sub-tropical to middle latitudes, but negative deviations more equatorward. Again, the location of the transition between positive and negative deviations is species dependent. The pattern below the $1-0.1 \mathrm{hPa}$ height region is most likely associated with upwelling in the tropical pipe which transports air from the tropical troposphere upwards.

At first glance, the deviation pattern of temperature above the $100 \mathrm{hPa}$ level (Fig. 6a) appears to match its counterparts in case of $\mathrm{N}_{2} \mathrm{O}$ (Fig. 7a), CFC-11, CFC-12, and $\mathrm{CH}_{4}$. If the deviation patterns of these species were to explain the temperature response, however, a positive mixing ratio deviation would have to increase the long-wave radiative heating. For realistic mixing ratio profiles it is well known that the opposite is true above the $100 \mathrm{hPa}$ level in case of $\mathrm{N}_{2} \mathrm{O}$ and $\mathrm{CH}_{4}$, and above the $30 \mathrm{hPa}$ level in case of CFC-11 and CFC-12 (e.g. Clough and Iacono, 1995).

Figure $7 \mathrm{~b}$ shows the relative difference in case of $\mathrm{O}_{3}$. As for the three species mentioned above, there is a positive deviation which increases towards the uppermost model layer, and it attains values of well beyond $+600 \%$. The 


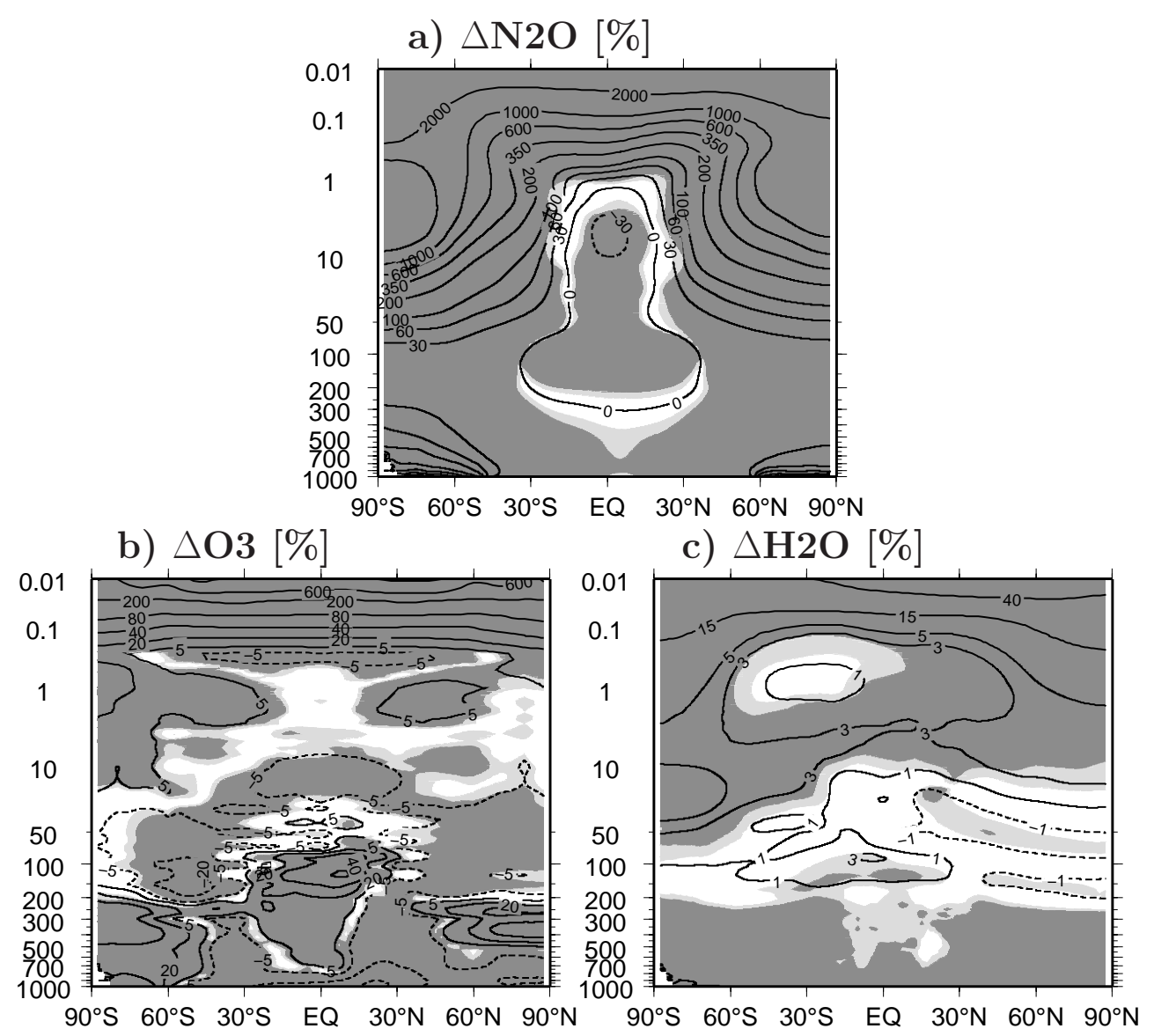

Fig. 7. Same as Fig. 6, but only for the per-cental deviation of simulation decoup full versus coup full (see Table 1) and offline fields in case of decoup full (a and b only). (a) $\Delta \mathrm{N}_{2} \mathrm{O}$ [\%], (b) $\Delta \mathrm{O}_{3}$ [\%], and (c) $\Delta \mathrm{H}_{2} \mathrm{O}$ [\%] (gaseous only). Note that in case of decoup full there are two different sets, offline and online, of the radiatively active species $\mathrm{N}_{2} \mathrm{O}, \mathrm{O}_{3}$, CFC-11, CFC-12, and $\mathrm{CH}_{4}$ : the radiation submodel RAD4ALL uses the offline climatologies, whereas chemistry and transport impact the online fields.

deviation is also considerable in absolute numbers. It reaches $+1 \times 10^{-6} \mathrm{~mol} \mathrm{~mol}^{-1}$, compared to $-0.5 \times 10^{-6} \mathrm{~mol} \mathrm{~mol}^{-1}$ at the $30 \mathrm{hPa}$ level in the tropics where the largest mixing ratios are.

As already mentioned, enhanced ozone mixing ratios cause a stronger local short-wave heating. This might well explain the distinct positive temperature deviation in the mesosphere, the region above the $1 \mathrm{hPa}$ level (Fig. 6a), and outweigh the intensification in long-wave cooling from $\mathrm{N}_{2} \mathrm{O}$, CFC-11, CFC-12, and $\mathrm{CH}_{4}$. Conversely, the positive deviation in mesospheric $\mathrm{O}_{3}$ mixing ratios could also explain the widespread negative deviation in stratospheric temperatures, in the height region between 100 and $1 \mathrm{hPa}$. The mechanism responsible is that stronger absorption in the mesosphere means less short-wave radiation is available to heat the stratosphere below.

To circumvent the aforementioned discrepancies, the radiation scheme of the QCTM simulation should be driven with appropriate offline climatologies of $\mathrm{O}_{3}, \mathrm{~N}_{2} \mathrm{O}, \mathrm{CFC}-11$, CFC12 , and $\mathrm{CH}_{4}$. It would be best to obtain these from the same coupled reference simulation that was used to derive the offline climatology of $\mathrm{HNO}_{3}$ (see Table 1). However, such is beyond the scope of this documentation.

Figure $6 \mathrm{~b}$ demonstrates the temperature effect without the radiation-induced contribution by the non- $\mathrm{H}_{2} \mathrm{O}$ species $\mathrm{O}_{3}$, $\mathrm{N}_{2} \mathrm{O}$, CFC-11, CFC-12, and $\mathrm{CH}_{4}$. Hence, the remaining effect is associated with the removal of $\mathrm{H}_{2} \mathrm{O}$-related feedback mechanisms (Sect. 3.4): the substitution of chemical $\mathrm{H}_{2} \mathrm{O}$ tendencies by climatological $\mathrm{CH}_{4}$ degradation, the omission of heterogeneous-chemical $\mathrm{H}_{2} \mathrm{O}$ tendencies, and the PSCrelated sedimentation of $\mathrm{H}_{2} \mathrm{O}$ made to "see" climatological $\mathrm{HNO}_{3}$ offline mixing ratios.

There are two obvious structures of temperature deviation. The tropical/subtropical mesosphere displays a deviation of $-0.6 \mathrm{~K}$, and the entire troposphere a deviation of about $-1 \mathrm{~K}$. Both structures appear to result from deviations of $\mathrm{H}_{2} \mathrm{O}$ and $\mathrm{O}_{3}$ (Fig. 8a and b): in the mesosphere, the positive $\mathrm{H}_{2} \mathrm{O}$ deviation increases long-wave radiative cooling, and the negative $\mathrm{O}_{3}$ deviation decreases short-wave radiative heating. The $\mathrm{H}_{2} \mathrm{O}$ deviation by itself results mainly from the 
Table 1. Simulations for the QCTM evaluation. All simulations cover the five-year period 1999-2003. Each experiment is conducted with the tropospheric dynamics nudged towards ECMWF operational-analysis fields for the period 1999-2003. These fields are pre-processed to generate the nudging data for divergence, vorticity, temperature, and surface pressure. The nudging forces the simulations to produce a similar sequence of variability, which is necessary due to the presence of feedbacks between chemistry dynamics in the simulations coup_full, coup_PSC, and coup_rad. The nudging reduces the noise in the simulation inter-comparisons and makes these better fulfill the normality assumption inherent to the paired t-test (Fomichev et al., 2007). Mixing ratios of total $\mathrm{HNO}_{3}$ from coup full are averaged on a monthly basis before fed into decoup_full and coup_rad. The setup for all simulations is: T42L90MA with EVAL chemistry (Jöckel et al., 2006), submodels CLOUD, CONVECT, CVTRANS, DRYDEP, H2O, HETCHEM, JVAL, LNOX, MECCA1, OFFLEM, ONLEM, PSC, QBO, RAD4ALL, SCAV, TIMEPOS, TNUDGE, and TROPOP.

\begin{tabular}{|c|c|}
\hline Experiment & Description \\
\hline decoup_full & $\begin{array}{l}\text { QCTM } \\
\text { input for RAD4ALL (in mol mol }{ }^{-1} \text { ): } \\
\mathrm{CO}_{2}: 348 \times 10^{-6} \text {, uniform (see Table A1) } \\
\mathrm{CH}_{4}: 1.65 \times 10^{-6} \text {, height decreasing (see Table A1) } \\
\mathrm{N}_{2} \mathrm{O}: 306 \times 10^{-9}, \\
\mathrm{CFC}-11: 280 \times 10^{-12}, \\
\mathrm{CFC}-12: 484 \times 10^{-12}, \\
\mathrm{O}_{3} \text { : climatology by Fortuin and Kelder (1998) } \\
\text { input for PSC: total-HNO } \mathrm{HN}_{3} \text { from simulation coup_full }\end{array}$ \\
\hline coup_full & fully coupled mode \\
\hline coup_PSC & $\begin{array}{l}\text { coupling only due to PSCs, } \\
\text { other settings as for decoup full }\end{array}$ \\
\hline coup_rad & $\begin{array}{l}\text { coupling only due to radiation, } \\
\text { other settings as for decoup_full }\end{array}$ \\
\hline
\end{tabular}

substitution of the online chemical $\mathrm{H}_{2} \mathrm{O}$ tendencies by climatological $\mathrm{CH}_{4}$ degradation, and the $\mathrm{O}_{3}$ deviation occurs as an effect to this. In the troposphere, a negative $\mathrm{H}_{2} \mathrm{O}$ deviation is known to reduce the long-wave heating, producing the negative temperature deviation in Fig. 6b. The tropospheric $\mathrm{H}_{2} \mathrm{O}$ deviation by itself is likely to arise from the omission of heterogeneous-chemical $\mathrm{H}_{2} \mathrm{O}$ tendencies as $\mathrm{CH}_{4}$ degradation plays a minor role in the water vapor budget there. Finally, the removal of non- $\mathrm{H}_{2} \mathrm{O}$ radiative feedback artificially compensates for the tropospheric deviation in temperature (Fig. 6a) and $\mathrm{H}_{2} \mathrm{O}$ (not shown).

Again, a remedy for these $\mathrm{H}_{2} \mathrm{O}$-related discrepancies would be to feed the QCTM simulation with appropriate climatological offline tendencies of $\mathrm{H}_{2} \mathrm{O}$. These should originate from the coupled reference simulation (see Table 1) and describe the tendencies of $\mathrm{H}_{2} \mathrm{O}$ from $\mathrm{CH}_{4}$ oxidation.

Figure 9a depicts the temperature deviation due to removal of feedback from PSC-related $\mathrm{H}_{2} \mathrm{O}$ sedimentation. The pat- tern of statistical significance is typical for type I random errors from multiple testing in the presence of spatial autocorrelation (von Storch and Zwiers, 1999). Hence, the deviations are not considered as robust, particularly for the southern polar lower stratosphere where PSCs most frequently occur. The same holds for mixing ratios of total $\mathrm{HNO}_{3}$ (Fig. 9b) and radiatively active substances such as $\mathrm{H}_{2} \mathrm{O}$ and $\mathrm{O}_{3}$ (not shown). The lack of deviation in temperature and tracer mixing ratios demonstrates that the approach is reliable.

\section{Conclusions}

A quasi chemistry-transport model mode, QCTM, has been implemented into the EMAC chemistry-climate model system. The QCTM is demonstrated to eliminate any feedback between chemistry and dynamics, which is a pre-requisite for meaningful sensitivity studies on the impact from small chemical perturbations. Such studies have been hampered by the feedback-triggered noise from the chaotic climate system.

Specifically, the elimination of radiation-induced feedbacks is achieved by feeding offline mixing ratios of radiatively active substances to the radiation scheme. An equivalent approach is not applicable in case of $\mathrm{H}_{2} \mathrm{O}$ as it feeds back on the model dynamics not only via the radiative transfer, but also via the hydrological cycle and other, PSC related, processes. In this case, the tendencies of $\mathrm{H}_{2} \mathrm{O}$ are disconnected from the KPP chemistry solver.

1. $\mathrm{H}_{2} \mathrm{O}$ tendencies from homogeneous chemistry are limited to climatological $\mathrm{CH}_{4}$ oxidation.

2. $\mathrm{H}_{2} \mathrm{O}$ tendencies due to thermodynamic re-partitioning are neglected.

3. $\mathrm{H}_{2} \mathrm{O}$ tendencies from PSC-related sedimentation are calculated using prescribed mixing ratios of $\mathrm{HNO}_{3}$.

Activation of the QCTM is accomplished by adjustment of certain namelist switches (see Table A1).

It is also required to feed the radiation scheme with appropriate offline fields of the radiatively active species, except $\mathrm{H}_{2} \mathrm{O}$, and the PSC scheme with appropriate offline fields of total $\mathrm{HNO}_{3}$. These fields should be compatible with the general chemical and dynamical characteristics of the QCTM simulation. Specifically, it is highly recommended to perform a coupled simulation with similar setup, derive mixing ratio climatologies of the relevant substances, and feed these into the associated QCTM simulation.

The two simulations in different mode, yet similar setup, are designed to yield consistent results. Hence, a comparison of the two simulations serves to evaluate the QCTM:

1. The offline fields of radiatively active species dominate the comparison. Associated inconsistencies can be large, especially in the mesosphere and the stratosphere, 

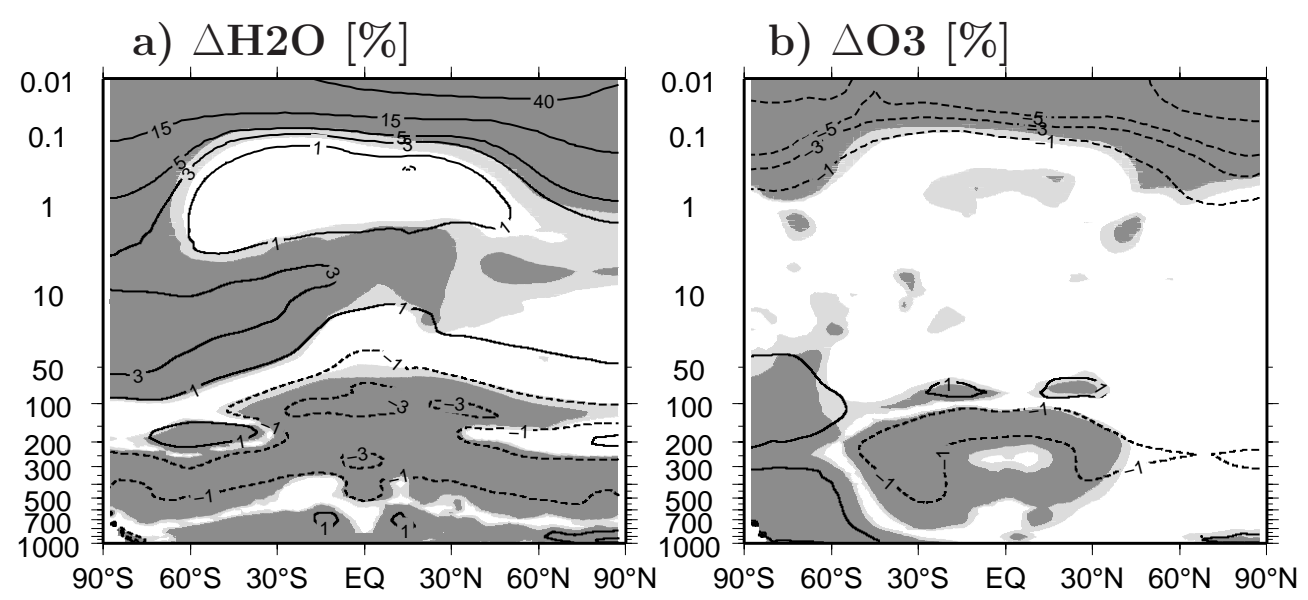

Fig. 8. Same as Fig. 6, but for the relative deviation of simulation coup_rad versus coup_full (see Table 1). (a) $\Delta \mathrm{H}_{2} \mathrm{O}[\%]$ (gaseous only), (b) $\Delta \mathrm{O}_{3}[\%]$.
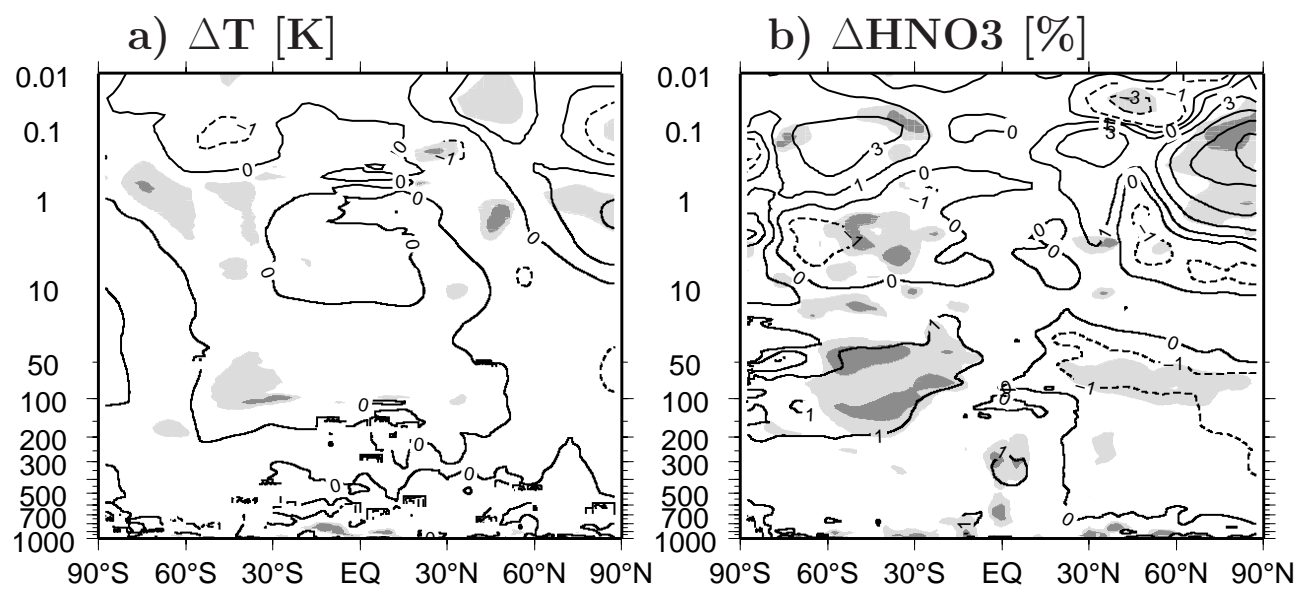

Fig. 9. Same as Fig. 6, but for the deviation of simulation coup psc versus decoup full (see Table 1). (a) $\Delta T$ [K], (b) $\Delta \mathrm{HNO}_{3}[\%]$ (sum of gaseous, liquid, solid).

so that a prescription of adequate offline fields is important.

2. The removal of PSC-related feedback is consistent.

3. Acceptably small inconsistencies are associated with the disconnection of the $\mathrm{H}_{2} \mathrm{O}$ tendencies from online chemistry.

Elimination of the inconsistencies under item 3 would require a prescription of the offline $\mathrm{H}_{2} \mathrm{O}$ tendencies from the coupled reference simulation. These should represent climatologically the $\mathrm{H}_{2} \mathrm{O}$ tendencies from homogenous chemistry and thermodynamic re-partitioning.

\section{Appendix A}

\section{Use of EMAC in QCTM}

This section exemplifies the use of EMAC in quasi chemistry-transport model mode (QCTM), and it is helpful to recapitulate some definitions. EMAC is run in QCTM when any impact from the model chemistry on the dynamics is switched off. The opposite case with active feedbacks between chemistry and dynamics is referred to as coupled mode. The model setup determines other model characteristics such as resolution, boundary conditions, and selection of active submodels. An offline field of chemical characteristics is imposed on a simulation from outside, whereas an online field is part of the simulation's chemistry integration. A reference simulation has a reference chemical setup from which the chemical setup of a sensitivity simulation differs slightly. 
Table A1. Namelist settings required to activate the QCTM for EMAC version 1.11 and higher. Regridding is referred to as rediscretization of an offline field to the ECHAM5 Gaussian grid (see Jöckel, 2006), triggering as the timed import of the re-gridded field into a running simulation (see Kerkweg et al., 2006).

\begin{tabular}{|c|c|}
\hline \multicolumn{2}{|c|}{ Offline climatologies of radiatively active species (example for $\mathrm{CH}_{4}$, analog for $\mathrm{CO}_{2}, \mathrm{O}_{3}, \mathrm{~N}_{2} \mathrm{O}, \mathrm{CFC}-11, \mathrm{CFC}-12$ ) } \\
\hline \multicolumn{2}{|l|}{$\& C P L$ in rad4all.nml } \\
\hline ch4vmr_rad4all = const. value & user-defined mixing ratio for ich4_rad4all $=2$ or 3 \\
\hline ich4_rad4all $=2 \quad$ or & whole atmosphere: mixing ratio set to $c h 4 v m r_{-}$rad 4 all \\
\hline ich4_rad4all $=3$ or & troposphere: ch4vmr_rad4all; decay with elevation above \\
\hline ich4_rad4all $=4$ & offline $\mathrm{CH}_{4}$ climatology \\
\hline & (preferred setting if climatology from coupled reference simulation) \\
\hline \multicolumn{2}{|l|}{ \&REGRID in rad4all.nml } \\
\hline var $=$ "CH4_init=CH4" & offline $\mathrm{CH}_{4}$ climatology: path and regridding setup \\
\hline \multirow{2}{*}{$\begin{array}{l}\text { \&RGTEVENTS in rad4all.nml } \\
R G_{-} T R I G(5)=\ldots\end{array}$} & \\
\hline & offline $\mathrm{CH}_{4}$ climatology: triggering setup \\
\hline \multicolumn{2}{|c|}{ Offline climatology of chemical $\mathrm{H}_{2} \mathrm{O}$ tendencies } \\
\hline \multicolumn{2}{|l|}{$\& C P L$ in $h 2 o . n m l$} \\
\hline I_H2O_TENDENCY $=2$ & offline climatological $\mathrm{CH}_{4}$ oxidation only \\
\hline \multicolumn{2}{|l|}{$\& C P L$ in hetchem.nml } \\
\hline$L_{-} C O U P L E \_H 2 O=F$ & no $\mathrm{H}_{2} \mathrm{O}$ tendencies from thermodynamic re-partitioning \\
\hline \multicolumn{2}{|c|}{ PSC-related partitioning of $\mathrm{H}_{2} \mathrm{O}$ based on offline climatology of total $\mathrm{HNO}_{3}$} \\
\hline \multicolumn{2}{|l|}{$\& C P L$ in psc.nml } \\
\hline$l_{-}$feedback $=F$ & $\begin{array}{l}\mathrm{H}_{2} \mathrm{O} \text { partitioning based on offline climatology of total } \mathrm{HNO}_{3} \\
\text { (preferably from coupled reference simulation) }\end{array}$ \\
\hline \multicolumn{2}{|l|}{$\& R E G R I D$ in offlem/psc_offline.nml } \\
\hline$v a r=$ 'predef_HNO3=HNO3_tot:INT' & offline total- $\mathrm{HNO}_{3}$ climatology: path and regridding setup \\
\hline \multicolumn{2}{|l|}{ \&RGTEVENTS in offlem.nml } \\
\hline$R G_{-} T R I G(40)=\ldots$ & offline total- $\mathrm{HNO}_{3}$ climatology: triggering setup \\
\hline \multicolumn{2}{|l|}{$\& C T R L$ in psc.nml } \\
\hline KinPar $=F$ & QCTM not tested for microphysical kinetic NAT scheme \\
\hline
\end{tabular}

In case of one reference simulation and a single sensitivity simulation it is usually required to perform three different simulations. All simulations should use the same executable. The reference simulation is implemented as two different simulations: once in coupled mode, once in QCTM. The coupled simulation serves to generate climatologies for input into the QCTM reference and sensitivity simulations. Hence, the coupled reference setup and the QCTM reference setup should be as similar as possible, and should usually differ only by the settings required to switch between coupled mode and QCTM (see Table A1). It is up to the user to decide on the length of the coupled simulation and on the details of the climatologies such as base period and temporal resolution.

The coupled simulation is accomplished first. Straightforward summation of the standard output variables $\mathrm{HNO}_{3}$ and $\mathrm{HNO}_{3}$ nat serves to establish a climatology of total- $\mathrm{HNO}_{3}$ mixing ratios. It goes into the QCTM simulations as input variable predef_HNO3_tot (see Fig. 3) and removes the PSCrelated feedbacks listed in Sect. 3.4 under items 2 and 3.

Also from the coupled simulation, climatologies of those radiatively-active species should be made which enter the ra- diative transfer as online fields (see rad4all.nml). This is usually the case for $\mathrm{O}_{3}, \mathrm{~N}_{2} \mathrm{O}, \mathrm{CFC}-11, \mathrm{CFC}-12$, and $\mathrm{CH}_{4}$. Again, the climatologies are fed into the two QCTM simulations as explained in Table A1. It is emphasized that the measures recommended in this paragraph do not apply to water vapor, which enters the radiative transfer as an online field in both QCTM and coupled mode.

The QCTM works as well for any arbitrary prescription of $\mathrm{O}_{3}, \mathrm{~N}_{2} \mathrm{O}, \mathrm{CFC}-11$, CFC-12, $\mathrm{CH}_{4}$, and predef_HNO3_tot. Yet, the offline fields made from an appropriate coupled simulation bring the climatological characteristics of coupled mode and QCTM close together. Even more important, it ensures consistency between the offline fields and the climatological characteristics of the QCTM simulation.

Finally, the desired response to small chemical perturbations follows from the difference between the two QCTM simulations, reference and sensitivity. In case of more than one sensitivity simulation it is not necessary to make further coupled reference simulations as the one applies to all sensitivities. 


\section{Appendix B}

\section{Usage of switch I_H2O_TENDENCY}

There are five different options for the switch I_H2O_TENDENCY in the CPL namelist of the $\mathrm{H} 2 \mathrm{O}$ submodel. Among these, the option I_H2O_TENDENCY $=2$ is the preferred setting for the QCTM (see also Sect. 3.2).

- IHH2O_TENDENCY $=-2$ or -1 : The $\mathrm{H}_{2} \mathrm{O}$ tracer is not synchronized with the specific humidity. The two options differ in the initialization of the $\mathrm{H}_{2} \mathrm{O}$ tracer during the EMAC start-up. Option -2: initialization from the specific humidity. Option -1 : initialization from satellite data in the stratosphere and the mesosphere in order to speed-up the spin-up.

- I_H2O_TENDENCY $=0$ : The $\mathrm{H}_{2} \mathrm{O}$ tracer and the specific humidity are synchronized, taking into account online $\mathrm{H}_{2} \mathrm{O}$-tracer tendencies from a chemistry submodel, e.g. MECCA1. Initialization of the $\mathrm{H}_{2} \mathrm{O}$ tracer is as for option -1 .

- I_H2O_TENDENCY = 1: Same as for option 0 , but an offline tendency from climatological $\mathrm{CH}_{4}$ oxidation is added to the online $\mathrm{H}_{2} \mathrm{O}$-tracer tendency.

- IHH2O_TENDENCY = 2: Same as for option 1, but only the offline $\mathrm{H}_{2} \mathrm{O}$-tracer tendency from climatological $\mathrm{CH}_{4}$ oxidation is accounted for.

Acknowledgements. The authors thank Benedikt Steil of the Max-Planck-Institut für Chemie, Mainz, who had prepared some important aspects of the QCTM implementation. They are also indebted to the Leibniz-Rechenzentrum, Garching, and to the Deutsches Klimarechenzentrum, Hamburg, where the simulations were done. The authors gratefully acknowledge the helpful comments on the manuscript by Mattia Righi, as well as the helpful discussions with Michael Ponater, both of the DLR - Institut für Physik der Atmosphäre, Oberpfaffenhofen. The contribution by Klaus-Dirk Gottschaldt has been funded by the HGF project AEROTROP. The work of Peter Hoor has been funded by the joint DFG/INSU-CNRS project POMODORO.

Edited by: A. Stenke

\section{References}

Buchholz, J.: Simulations of physics and chemistry of polar stratospheric clouds with a general circulation model, $\mathrm{PhD}$ thesis, Johannes Guttenberg University Mainz, 2005.

Clough, S. and Iacono, M.: Line-by-line calculation of atmospheric fluxes and cooling rates 2. Application to carbon dioxide, ozone, methane, nitrous oxide and the halocarbons, J. Geophys. Res., 100, 16519-16535, 1995.

Damian, V., Sandu, A., Damian, M., Potra, F., and Carmichael, G.: The kinetic preprocessor KPP - a software environment for solving chemical kinetics, Comput. Chem. Eng., 26, 1567-1579, 2002.
Fomichev, V. I., Jonsson, A. I., de Grandpré, J., Beagley, S. R., McLandress, C., Semeniuk, K., and Shepherd, T. G.: Response of the middle atmosphere to $\mathrm{CO}_{2}$ doubling: results from the Canadian Middle Atmosphere Model, J. Climate, 20, 11211144, 2007.

Fortuin, J. and Kelder, H.: An ozone climatology based on ozonesonde and satellite measurements, Clim. Dynam., 103, 31709-31734, 1998.

Hoor, P., Borken-Kleefeld, J., Caro, D., Dessens, O., Endresen, O., Gauss, M., Grewe, V., Hauglustaine, D., Isaksen, I. S. A., Jöckel, P., Lelieveld, J., Myhre, G., Meijer, E., Olivie, D., Prather, M., Schnadt Poberaj, C., Shine, K. P., Staehelin, J., Tang, Q., van Aardenne, J., van Velthoven, P., and Sausen, R.: The impact of traffic emissions on atmospheric ozone and $\mathrm{OH}$ : results from QUANTIFY, Atmos. Chem. Phys., 9, 3113-3136, doi:10.5194/acp-9-3113-2009, 2009.

Jöckel, P.: Technical note: Recursive rediscretisation of geoscientific data in the Modular Earth Submodel System (MESSy), Atmos. Chem. Phys., 6, 3557-3562, doi:10.5194/acp-6-35572006, 2006.

Jöckel, P., Tost, H., Pozzer, A., Brühl, C., Buchholz, J., Ganzeveld, L., Hoor, P., Kerkweg, A., Lawrence, M. G., Sander, R., Steil, B., Stiller, G., Tanarhte, M., Taraborrelli, D., van Aardenne, J., and Lelieveld, J.: The atmospheric chemistry general circulation model ECHAM5/MESSy1: consistent simulation of ozone from the surface to the mesosphere, Atmos. Chem. Phys., 6, 50675104, doi:10.5194/acp-6-5067-2006, 2006.

Kerkweg, A., Sander, R., Tost, H., and Jöckel, P.: Technical note: Implementation of prescribed (OFFLEM), calculated (ONLEM), and pseudo-emissions (TNUDGE) of chemical species in the Modular Earth Submodel System (MESSy), Atmos. Chem. Phys., 6, 3603-3609, doi:10.5194/acp-6-3603-2006, 2006.

Kirner, O., Ruhnke, R., Buchholz-Dietsch, J., Jöckel, P., Brühl, C., and Steil, B.: Simulation of polar stratospheric clouds in the chemistry-climate-model EMAC via the submodel PSC, Geosci. Model Dev., 4, 169-182, doi:10.5194/gmd-4-169-2011, 2011.

Roeckner, E., Brokopf, R., Esch, M., Giorgetta, M., Hagemann, S., Kornblueh, L., Manzini, E., Schlese, U., and Schulzweida, U.: Sensitivity of simulated climate to horizontal and vertical resolution in the ECHAM5 atmosphere model, J. Climate, 19, 3771-3791, 2006.

Sander, R., Kerkweg, A., Jöckel, P., and Lelieveld, J.: Technical note: The new comprehensive atmospheric chemistry module MECCA, Atmos. Chem. Phys., 5, 445-450, doi:10.5194/acp-5445-2005, 2005.

Steil, B., Brühl, C., Manzini, E., Crutzen, P. J., Lelieveld, J., Rasch, P. J., Roeckner, E., and Krüger, K.: A new interactive chemistry-climate model: 1 . Present-day climatology and interannual variability of the middle atmosphere using the model and 9 years of HALOE/UARS data, J. Geophys. Res., 108, D4290, doi:10.1029/2002JD002971, 2003.

Unger, N., Shindell, D., Koch, D., and Streets, D.: Air pollution radiative forcing from specific emissions sectors at 2030, J. Geophys. Res., 113, D02306, doi:10.1029/2007JD008683, 2008.

von Storch, H. and Zwiers, F.: Statistical analysis in climate research, Cambridge University Press, Cambridge, 1999.

WMO: Scientific assessment of ozone depletion: 2006, vol. 50, in: Global Ozone Res. Monit. Proj. Rep., World Meteorological Organization, Geneva, Switzerland, 2007. 